\title{
Orthodox Christianity and gender through a religion-as-lived perspective
}

Orthodox Christianity and Gender:

Dynamics of Tradition, Culture and Lived

Practice, eds. Helena Kupari and Elina

Vuola, Routledge Studies in Religion

(London and New York: Routledge, 2020),

224 pp. Open access publication: <https:// doi.org/10.4324/9780203701188>.

While a growing number of scholars today direct their attention towards religion as an aspect of daily life, the study of religions certainly still has a disciplinary 'bias towards textuality', as Ole Riis and Linda Woodhead (2010:3) phrase it. This preoccupation with religions as coherent systems of thought structures of moral reasoning to be defined and debated - has resulted in a neglect of the emotional, bodily and relational aspects of religious everyday life; perspectives that contribute to an image of human religiosity as something more colourful, complex, contradictory and changing than the neat presentations of religions as clear-cut sets of institutionally sanctioned creeds and conducts found in many textbooks.

Over the past decades several approaches have developed to counter this imbalance by creating more inclusive theories and methods for researching religion. While the bias towards textuality certainly has been challenged, however, the challenge

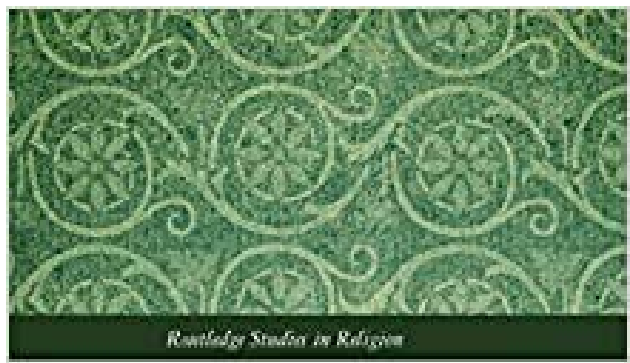

\section{ORTHODOX CHRISTIANITY AND GENDER}

OYNAMICS OF TRADITION, CULTURE ANO LIVEO PRACTICE

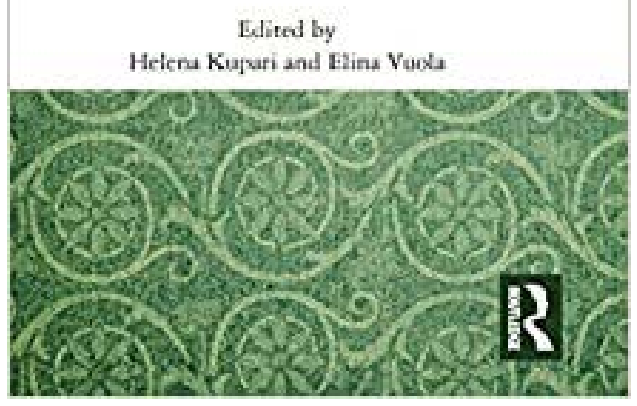

of including a plurality of voices into the research on everyday religion remains. Most studies applying such frameworks are built on narrow data sets derived from (Western) Christian contexts. Therefore, the recent volume Orthodox Christianity and Gender: Dynamics of Tradition, Culture and Lived Practice makes a strong and welcome contribution to the field, significantly 
broadening its scope. Edited by the scholars of religion Helena Kupari and Elina Vuola, both attached to the University of Helsinki, it examines Orthodox Christianity from a gender-sensitive perspective.

In eleven chapters, the volume sheds light on the 'myriad ways in which gender is manifested, performed, and engaged within contemporary Orthodoxy' (p. 2). The editors have sought to include contributions that, taken together, display both similarities and differences in the local, lived expressions of Orthodoxy. The authors represent a broad array of disciplines such as folklore studies, theology, sociology, art history, religious studies and anthropology, and deal with varied geographical and historical contexts in their research. Most chapters centre on empirical case studies while not excluding theological discussions in their investigations into lived expressions of faith and local practice. The chapters are divided into three parts: 'Negotiating tradition', 'Lived Orthodoxy', 'Crisis and gender'. In addition to Finnish researchers, scholars tied to universities in Canada, Estonia, Germany, Russia, South Africa, Ukraine and the USA contribute to the volume: Brian A. Butcher, Nadezhda Beliakova, Katariina Husso, Peter-Ben Smit, Andreas Kalkun, Sarah RiccardiSwartz, Pekka Metso, Nina Maskulin, Teuvo Laitila, Heleen Zorgdrager, Eleni Sotiriou and Elena Romashko.

The volume creates a compelling overview of the research field. It shows how Orthodox Christianity can offer an exceptionally fruitful field for investigating gender, embodiment and sexuality, as this tradition generally 'emphasizes the sacramentality or sacredness of reality, including the natural and material world, as the primary sign of God's mercy and love' (p. 6). Nevertheless, like all Christian institutions, the Orthodox church also displays a long history of excluding and denigrating women, the body and sexuality in their theology and practice. Hence, the table is set for fascinating explorations from an angle doubly invisible in mainstream research: gendered everyday religiosity in the Christian Orthodox world.

The editors' introduction to the volume functions as a pertinent guide to the research field and offers a comprehensive summary of the topical themes and perspectives for readers of different disciplinary backgrounds. An interesting discussion, with broad relevance for researchers of religion in general, concerns the notion religion-as-lived, which it seems Kupari and Vuola are coining in this volume while not explicitly claiming to introduce new terminology. This term comprises the widely applied notion of lived religion, paralleled by approaches such as vernacular religion and everyday religion. All of them place individual experiences in dialogue with overarching structures, and intellectual dimensions with emotional ones, without portraying them as binary opposites in a hierarchical system of established norms against vulgar popularisations. Thus, religion-as-lived focuses primarily on religious activities that take form outside of organised, institutional practices, on the many ways in which religion feeds into personal life-narratives and on innovative practices where secular, religious and spiritual dimensions meet in ordinary people's day-to-day life. Attention is paid to individuals and groups who represent perspectives at the margins of influence and power due to aspects of gender, age, ethnicity, sexuality, class or the like.

Lived religion stems from the sociology of religion, while vernacular religion has its roots in a different academic discipline: folklore studies. While the approaches therefore tend to differ slightly in emphasis and expression, both aim to capture 
religion as a complex and changing component of life: a lived reality formed by emotions, bodies, thoughts and mundane worries, but also tied to the larger social, historical and institutional structures that set the conditions for and form the context of the personal religious path. Thus, the editors argue, they can be collectively described as the study of religion-aslived, and the articles in the volume aptly exemplify the slight but significant variations in focus facilitated by the different approaches. To exemplify the vernacular approach, for example, Elena Romashko and Sarah Riccardi-Swartz bring out characteristically folkloristic themes such as narrative structures and local practices in their analyses.

As part of the religion-as-lived framework, two important perspectives relevant throughout the volume are introduced: material and embodied piety as well as religious agency. As noted above, material and corporeal expressions of religiosity, emotions and embodiment are increasingly attracting the interest of researchers of religion. In line with this effort, the current volume calls the incompatibility of materiality and spirituality into question and offers plenty of examples of embodied and material Orthodox practices that can be fruitfully analysed from a gender perspective: gestures and rituals, 'foodways' and fasting, and clothing, to name a few. In relation to religious agency, the Orthodox context offers an eye-opening example of how especially women's capacity for action, in a religious sphere formed by a hesitant and sometimes even rejecting attitude towards Western norms of modernity, displays a vast array of strategies stretching from pious observation to pragmatic realism and innovative applications. Women's agency in traditional religions is all too often depicted as strategies of empowerment applied to reach social, political or personal goals. However, the articles in this volume show that agency can also be a genuinely existential undertaking: a mode of being in its own right and a pursuit to become an authentic religious subject in a male-dominated, overtly secular world.

The volume should be of interest to students and researchers of both religious studies and theology as well as gender studies, who want to learn more about any of the themes covered by the volume: the Orthodox church, religion-as-lived or religion and gender. The combination of the themes in the current volume fills an apparent void in current scholarship. Finally, the volume also contributes to the advancement of open science in a splendid way as it is published open access online for all readers to indulge without costly subscriptions or licenses.

Ruth IIIman

Ruth IIIman is the Director of the Donner Institute for Research in Religion and Culture in Åbo/ Turku, Finland. She is a docent of the study of religions at Åbo Akademi University and of the history of religions at Uppsala University. Her main research interests include contemporary Judaism, interreligious dialogue and cultural encounters as well as religion and the arts.

\section{Reference}

Riis, Ole, and Linda Woodhead. 2010. A Sociology of Religious Emotion (Oxford University Press). 